\section{Entrevista: Danièle Linhart}

Interview: Danièle Linhart
A socióloga Danièle Linhart é professora da Universidade Paris $\mathrm{X}$ - Nanterre e pesquisadora do Centro Nacional de Pesquisa Científica (Centre National de la Recherche Scientifique - CNRS), onde está vinculada ao Laboratório Gênero, Trabalho e Mobilidade, do Centro de Pesquisas Sociológicas e Políticas de Paris (Laboratoire Genre, Travail et Mobilité/Centre de Recherches Sociologiques et Politiques de Paris - GTM/CRESSPA). Realiza pesquisas sobre as transformações na organização e gestão do trabalho na empresa moderna, sendo autora de vários livros que tratam desta temática, como a coletânea publicada no Brasil, em 2007, A desmedida do capital. Participa, como coordenadora na França, do acordo de cooperação internacional Capes-Cofecub, que envolve a Faculdade de Educação da Universidade Estadual de Campinas (Unicamp). Cofecub é a sigla de Comité Français d'evaluation de la coopération universitaire avec le Brésil (Comitê Francês de Avaliação da Cooperação Universitária com o Brasil). A realização desta entrevista se deu no âmbito do desenvolvimento de atividades relativas à cooperação entre a Fundação Oswaldo Cruz (Fiocruz) e o CNRS, a propósito de estudos sobre a relação gênero, saúde e trabalho. Nesta entrevista, ${ }^{1}$ Linhart aborda a questão que denomina de penosidade do trabalho, a partir de uma análise das modernizações em curso. Trata ainda dos aspectos subjetivos presentes no mundo produtivo atual, assim como faz reflexões sobre os casos de suicídio ocorridos recentemente em empresas francesas.
Sociologist Danièle Linhart is a professor at Paris $\mathrm{X}$ - Nanterre University and a researcher at the National Center for Scientific Research (NCSR), which has ties to the GTM/CRESSPA - Laboratory of Gender, Work, and Mobility, at the Paris Center for Sociological and Political Research. She conducts research on the changes in the organization and management of work at modern enterprises, and has authored several books dealing with this issue, such as the collection published in Brazil in 2007 titled $A$ desmedida do capital (The imbalance of capital). She is the coordinator, in France, of the Capes-Cofecub international cooperation agreement that involves the College of Education of the University of Campinas (Uncamp). This interview took place in ambit of the development of activities relating to the cooperation between the Oswaldo Cruz Foundation (Fiocruz) and CNRS with regard to studies on the relationship among gender, health, and work. In this interview, Linhart discusses what she calls the difficulty of work, analyzing the modernization processes that are currently underway. She also deals with subjective aspects of the present productive world, and reflects on the recent cases of suicide in French companies. 


\section{Revista}

A senhora pode nos falar de seus últimos objetos de pesquisa?

\section{Danièle Linhart}

A última pesquisa da qual gostaria de falar é a que coordenei dentro de um projeto de pesquisa da ANR [Agence Nationale de Recherche/Agência Nacional de Pesquisa], sobre a modernização das penosidades do trabalho. Ela durou três anos, de 2007 a 2010, e se baseou essencialmente em três campos de investigação: vendedores de um grande shopping center (pesquisa realizada por Julien Choquet), representantes comerciais e condutores de trem de uma grande empresa de transportes (pesquisa realizada por Sabine Fortino) e professores do ensino médio (pesquisa que eu mesma realizei). Também fiquei encarregada da síntese dessas três monografias e relatarei aqui os aspectos que mais chamam a atenção.

As penosidades sempre fizeram parte do mundo do trabalho, pois este se caracteriza pelas restrições que ele impõe aos indivíduos e necessariamente constitui veículo de desacordos, dificuldades que ressoam em todas as dimensões da existência. Mas, bem contemporaneamente, a temática das penosidades tomou força e entra em ressonância com o tema onipresente do sofrimento no trabalho. O trabalho tende a ser associado à ideia de mal-estar e de uma possibilidade tão presente de dano psicológico que pode até conduzir ao suicídio, ou pelo menos à depressão. Os indivíduos que conhecemos durante a pesquisa designam como penosidades as dificuldades com as quais não conseguem lidar ou que não conseguem dominar, que surgem como estranhas à sua profissão, que encontram origem em lógicas profissionais diferentes das que os motivam, que se inscrevem em outro registro de valores, que não lhes parecem equitativamente divididas e às quais esses indivíduos não conseguem mais atribuir um sentido. São penosidades, porque lhes parecem injustificadas, quer elas firam sua identidade profissional ou sua autoimagem, quer sejam vividas como um não reconhecimento da suas necessidades de fazer um trabalho de qualidade, verdadeiramente profissional.

\section{Revista}

A senhora pode falar um pouco mais sobre as penosidades associadas à identidade profissional?

\section{Danièle Linhart}

Análises sociológicas e ergonômicas enfatizaram muito a importância dos coletivos para diminuir ou conter as dificuldades do trabalho, suscetíveis de causar sofrimento, graças à produção clandestina ou invisível de saber, um saber-fazer que permite realizar corretamente o trabalho em condições que administrem e acomodem os esforços e os desgastes (tanto fisiológicos quanto psicológicos). Elas evidenciaram o trabalho real, a regulação autônoma em relação ao trabalho prescrito, que leva em consideração as exigências, as restrições, a necessidade dos indivíduos se pouparem, de se protegerem, de manter um interesse no que fazem quando estão no trabalho. Elas evidenciaram a capacidade desses coletivos de inventar e colocar em cena regras de jogo informais que abrem espaço para a ajuda mútua, a solidariedade, sua capacidade de compartilhar valores ligados a uma experiência comum, valores com conotação sindical, política ou profissional. Esses coletivos podiam assim, de certa forma, minimizar o sofrimento de duas maneiras, reduzindo-o objetivamente pela ajuda mútua e dando-lhe um sentido coletivo: o sofrimento no trabalho era colocado em referência à relação de força, à exploração e à dominação, ele se explicava em vista dos interesses econômicos e políticos. E os coletivos, por meio de sua ação, tentariam se contrapor à hierarquia e à direção para procurar diminuir esse sofrimento. Vários textos sociológicos se dedicaram à análise da modernização das empresas, que se esforçou para quebrar a dimensão coletiva do trabalho, por uma polivalência, uma mobilidade e uma concorrência sistemáticas, e formas de gestão personalizada: instauração de horários variados, bônus individualizados e salários também individualizados, difusão da lógica de prestações de serviço com seus próprios recursos e, por fim, entrevistas individuais com o chefe durante as quais cada assalariado deve 'negociar' com seu superior hierárquico imediato seus objetivos, suas tarefas e passar por uma avaliação de desempenho no final do ano.

O coletivo, entendido como um grupo estável de assalariados trabalhando juntos, em proximidade física, não é o único recurso que os trabalhadores usam para se proteger das dificuldades e para superá-las. Não se trata de minimizar a importância dos coletivos: ela é bem real e vários especialistas em Ciências Sociais puderam cons- 
tatar que a individualização vulnerabiliza os assalariados. Mas existe também um cabedal e um referencial comuns que os sobrepujam e se cristalizam no ofício e em suas regras, qualquer que seja seu reconhecimento externo, e que se referem ao que Yves Clot chama de 'premeditado social em movimento'.

Nosso trabalho de campo permitiu abordar esses referenciais no exato momento em que são questionados, em momentos perigosos para os trabalhadores, em que o próprio sentido de seu trabalho e os valores que ele veicula são submetidos a uma reelaboração externa. A maneira como esses trabalhadores podem ou não fazer face a essa reelaboração condiciona a emergência das penosidades, isto é, dificuldades que eles não sabem mais gerir.

O que nos indicam nossos diferentes campos de pesquisa é ilustrado pela importância da legitimidade ou ilegitimidade dessas evoluções aos olhos de quem elas se referem e de cujo trabalho é afetado por elas. Se as condições de exercício do trabalho (seu conteúdo, sua finalidade, suas modalidades) parecem mudadas, aos olhos dos profissionais em questão, em oposição ou descompasso com os elementos fundamentais das regras da profissão ou as regras do jogo explícito ou tácito segundo as quais se organiza toda a vida no trabalho, a sensação de penosidade surgirá com força ainda maior. Se elas aparecem como arbitrárias ou baseadas em uma falta de confiança nas competências ou no estado de espírito dos trabalhadores, a mesma sensação de incômodo se imporá. E o mesmo acontece se elas aparecem como impostas sem qualquer consulta aos profissionais envolvidos e fora de qualquer deliberação quanto à validade das mudanças e suas consequências.

Parece que o incômodo nasce de uma impossibilidade de aderir às evoluções que redefinem o trabalho, seja porque entram em contradição com os referenciais comuns do ofício, validados individualmente, seja porque confundem as regras do jogo sobre as quais se baseiam uns e outros, seja porque aparecem como uma manifestação da relação de força que opõem assalariados e direções, como um ato arbitrário para exercer um controle mais decisivo sobre os assalariados, negando-lhe qualquer possibilidade de contribuir para a atualização, a reelaboração das regras de seu trabalho. A penosidade vem da sensação de injustiça e de desordem, acrescida à de im- potência. Quando este sentimento é vivido de forma individual sem o apoio do grupo, capaz de relativizá-lo pelo simples fato de compartilhá-lo, adquire, sem dúvida, mais força, com risco de 'afogar' os indivíduos. A penosidade surge quando se reafirma e se mostra a ferocidade do contrato de trabalho, que é um contrato de subordinação jurídica estipulando o tempo do assalariado que pertence ao empregador, que o organiza e o utiliza em função de seus interesses próprios e da própria lógica, negando ao assalariado um direito de olhar para a forma como o tempo é empregado no trabalho. Isso se verifica tanto no setor privado quanto no setor público.

\section{Revista}

A senhora pode explicar a associação das penosidades com o não reconhecimento das necessidades de fazer um trabalho de qualidade?

\section{Danièle Linhart}

A desestabilização das profissões e identidades profissionais aparece através dos campos de pesquisa como uma estratégia deliberada da administração modernista. Essa desestabilização não é apenas a consequência de outras políticas aplicadas nessa modernização; ela corresponde à adoção de uma política que visa minimizar os custos e restringir e controlar os assalariados. É pelo menos assim que vários entrevistados interpretam as evoluções a que estão submetidos. Eles se sentem alvo de políticas que visam despossuí-los de meios de dominar seu trabalho e de realizá-lo em condições satisfatórias para eles mesmos, assim como para seus destinatários.

As formas de racionalização aplicadas, polivalência, mobilidades sistemáticas, enquadramento cada vez mais estrito das atividades e do tempo passado no trabalho com avaliações e objetivos atribuídos pela hierarquia cada vez mais limitantes, a padronização das atividades, diminuição dos meios, individualização que encontramos em diferentes campos visariam manter os assalariados em estado de insegurança e de dependência. Nas situações de trabalho não industriais, são modalidades de organização e de gerenciamento de inspiração taylorista que enquadram cada vez mais a atividade de trabalho. Trata-se ao mesmo tempo de diminuir os custos, mas também de expropriar os trabalhadores do domínio de seu trabalho e da capacidade de interpretar sua finalidade e seus fundamentos. O objetivo é 
minimizar a capacidade dos trabalhadores de fazer oposição, impor resistência, diante das exigências das direções. Criar um tipo de precariedade subjetiva para que os trabalhadores não se sintam à vontade no trabalho nem entre eles, para que não possam desenvolver redes de cumplicidade e de apoio com os colegas, com a hierarquia, nem com seus clientes, a fim de que sintam sempre a corda esticada e fiquem mais receptivos às injunções que visam aumentar a rentabilidade de seu trabalho. Essa lógica se expressa ainda melhor no setor público, sujeito a uma modernização modelada pela LOLF [Loi Organique Relative Aux Lois de Finances/Lei de Orientação das Leis Financeiras] e pela RGPP [Révision Générale des Politiques Publiques/Reforma Geral das Políticas Públicas] e nas empresas públicas confrontadas com o fim do monopólio.

\section{Revista}

Em suas últimas publicações, a senhora disse que a subjetividade é um assunto incontornável para os sociólogos do trabalho. Quais são, em sua opinião, os aspectos da subjetividade mais importantes neste momento?

\section{Danièle Linhart}

A sociologia não se predispõe a se interessar pela subjetividade, que é o campo privilegiado da psicologia. A partir do momento em que se aborda a questão da subjetividade no trabalho, a sociologia, ciência da sociedade vinculada à inteligibilidade das relações entre indivíduos, e do que compõe a sociedade, enfrenta um desafio. A subjetividade é, na verdade, o que se liga ao indivíduo, a sociologia se dedica à relação entre o indivíduo e a sociedade, e à compreensão da sociedade mais do que à do indivíduo.

Acontece que a subjetividade de repente ressurgiu no âmago do mundo do trabalho e se impôs como objeto incontornável de pesquisa para os sociólogos do trabalho. Pois os gerentes passam hoje a se reportar diretamente à subjetividade dos assalariados e afirmam a necessidade de mobilizá-la para garantir o desempenho das empresas. A subjetividade se tornou explicitamente para os gerentes uma fonte indispensável para novas formas de organização do trabalho e sua mobilização alardeada como prova de ruptura com as formas anteriores e principalmente com o taylorismo que, ele próprio, não teria exigido a mobilização subjetiva dos assalariados.
A subjetividade é, então, apreendida por meio do que caracteriza a pessoa diante, diferentemente de ferramentas, de máquinas e outros recursos produtivos, isto é, por meio de suas dimensões cognitivas, seu registro emocional, afetivo e moral, em relação também com a biografia, uma trajetória particular, o que torna a pessoa diferente das outras e, portanto, não substituível.

Essa subjetividade de novo exigida, que parece encontrar enfim o seu lugar, sempre esteve bem presente no seio de todas as formas anteriores de organização, por mais taylorizadas que fossem. Ela sempre foi indispensável para dar sentido e operacionalidade a formas prescritivas que teriam ficado praticamente inertes, sem implicação subjetiva e, com frequência, até mesmo transgressora para os assalariados mais subalternos. Basta pensar no que representa uma 'greve de zelo', que não é nada mais do que o cumprimento de prescrições e normas operatórias sem interpretação e adaptações de instruções: simplesmente as coisas não andam mais. Então, um ramo importante da sociologia do trabalho, ao lado da ergonomia, analisou em profundidade e estudou essa dimensão sempre presente da implicação dos assalariados para além do que era explicitamente exigido deles, pois como dizia Desbrousses e Peloille, nas situações de trabalho mais taylorizadas, "se a alma está aprisionada, ela é exigida o tempo todo". 2 Não se poderia conceber uma mobilização cognitiva sem implicação subjetiva, sem uma contribuição da inteligência da pessoa, de seus afetos e de sua relação com o mundo. Um corpus importante da sociologia do trabalho trabalhou essa questão (principalmente $\mathrm{Ph}$. Bernoux, ${ }^{3}$ D. Linhart,4 J. D. Reynaud, 5 G. de Terssac $^{6}$ ) sem quase nunca se deter nos motivos que levam os assalariados a essa implicação (ao menos paradoxal, na medida em que reforça a exploração tornando a norma taylorista mais operacional e, portanto, mais eficaz). Excetuando-se algumas tentativas de desvendar essa questão, 7 é preciso dizer que a subjetividade, em sua forma clandestina, não era tratada como tal, mas analisada na sua funcionalidade para a organização taylorista do trabalho.

Nesse sentido, é preciso se perguntar sobre a vontade de ruptura com a lógica taylorista apregoada pela administração modernista e sua pretensão de reservar outro lugar para essa subjetividade dos assalariados. Várias análises sociológicas 8 
enfatizam um objetivo de racionalização, uma vontade de formatar essa subjetividade para que ela se harmonize com os métodos impostos e, principalmente, a cultura gerencial da empresa. A modernização do trabalho e das empresas se caracteriza por uma reabilitação da subjetividade dos assalariados e sua mobilização nos termos exigidos segundo a racionalidade dominante da empresa, em outras palavras, para subordiná-la. Essa subjetividade só é, na realidade, reconhecida a partir do momento em que se torna objeto de uma ação que visa canalizá-la, controlá-la, estimulá-la e envolvê-la em uma situação muito precisa, pré-construída. Todo um conjunto de medidas é necessário, da aplicação de códigos de comportamento ou de ética ${ }^{9}$ a uma gestão muito individualizada, colocando sistematicamente os assalariados em concorrência, passando por formações bem demarcadas e pela imposição de objetivos imperiosos e delimitados. A própria organização é com frequência concebida como uma estrutura que canaliza os esforços para uma forma única de atitude e comportamentos profissionais, 10 tudo isso constituindo como expressa Marie-Anne Dujarrier um “ideal de trabalho"11 dificilmente atingível, onipresente e funcionando como uma incitação permanente sob a forma de condicionamento.

\section{Revista}

Como a dimensão subjetiva do trabalho aparece nas pesquisas que a senhora desenvolve?

\section{Danièle Linhart}

As contribuições da obra Pourquoi travaillonsnous? 12 [Por que trabalhamos?] que dirigi, assim como as indagações mobilizadas em meu livro Travailler sans les autres?13 [Trabalhar sem os outros?], todas realizadas a partir de pesquisas de campo, estudos de casos, põem em evidência uma necessidade de afirmação da sociedade na construção de si mesma pelo trabalho.

Uma inscrição da norma social no uso de si no trabalho parece não ser imposta ou consentida, mas solicitada: a submissão a uma norma social é, em si, constitutiva de uma sensação de pertencimento à sociedade, e uma certa dimensão de desapossamento de si em prol de lógicas definidas alhures é reconfortante para a construção da subjetividade.

Os psicólogos em geral e os profissionais ligados à Psicodinâmica do Trabalho, em particular, ates- tam: longe de ser uma questão entre o indivíduo consigo mesmo, a subjetividade, ao contrário, se nutre, cresce no encontro com o outro e com o confronto com outras lógicas. Trata-se de um processo de elaboração permanente em que o trabalho desempenha um papel essencial, pois permite exatamente se aventurar fora de si. O trabalho introduz uma demarcação consigo mesmo, uma inscrição na história comum. Como diz D. Lhuilier: "A maioria das pessoas ressalta o quanto o exercício profissional as modificou, a necessidade de uma clivagem entre sua vida profissional e sua vida privada, como se a dissociação de si mesmos pudesse constituir uma garantia de inocuidade na carga pulsional ligada às tarefas repressivas, uma proteção de sua identidade pessoal posta à prova."14 Para Y. Clot, no trabalho, o sujeito é "obrigado a aceitar uma tradição que o desapruma". De certa forma, nos diz ele, o trabalho contém algo "de estruturalmente impessoal", inscrevendo o sujeito entre seus semelhantes, em uma cadeia de gerações. $\mathrm{O}$ trabalho é um esforço pessoal dirigido a "um destinatário ausente: a existência de todos, este outro radical, que faríamos de bom grado, para falar como Baktin, o 'sobredestinatário' do esforço consentido". 15

O sociólogo se sente interpelado por este 'estruturalmente impessoal' (que não é mais do que a heteronomia do trabalho), por este 'sobredestinatário' (que não é mais do que a sociedade), que, aliás, não é apenas 'sobredestinatária', mas também comanditária. É nessa perspectiva que ele pode se pôr no lugar do outro, se interrogando sobre a influência desse 'outro radical' que é o conjunto de todos.

Para o sociólogo, parece que o importante no trabalho é essa existência da força do comanditário que exige a contribuição de cada um e que a distingue com sua marca. O que cada um faz no trabalho tem a ver com a finalidade de todo trabalho, isto é, ser da sociedade, fazendo parte dela e a fazendo existir, mas também tem a ver com a maneira de fazê-lo. Cada um deve e quer fazer validar o que faz por meio de uma série de cumprimentos de regras, de condicionamentos de si mesmo, segundo uma lógica que lhe é exterior enquanto indivíduo, mesmo que ela não lhe seja estranha enquanto membro da sociedade. Uma parte da subjetividade corresponde a essa busca: não pertencer totalmente ao trabalho para pertencer à sociedade. Longe de 
ser exclusivamente o que resiste à dominação, a subjetividade no trabalho se nutre também dessa presença reconfortante apesar de dominadora da sociedade. É ela que faz sentido. Várias contribuições das duas obras a que me refiro trazem esclarecimentos a respeito dessa dominação buscada, e até mesmo cobiçada, sob diversas formas que apresentaremos com mais detalhes. Outras contribuições, no entanto, enfatizam as formas de controvérsias quanto a esse tributo a pagar, não em torno de sua existência, mas em torno de seu conteúdo, principalmente moral. Quando outros, por fim, mostram que as condições nas quais os indivíduos se libertam desta dominação têm uma influência sobre seu lugar simbólico na família e na vida fora do trabalho. Na verdade, tudo se joga segundo os termos do diálogo posto entre o trabalho e a sociedade.

É a partir do campo que se impõe, na verdade, essa dimensão da realidade, ou pelo menos da sua experiência. Parece que essa necessidade de uma responsabilização e de uma validação de si mesmo pela restrição social é uma forma que a subjetividade pode assumir mesmo que ela afaste o indivíduo de interesses que lhe seriam mais específicos ou próprios. A dependência, a configuração de si mesmos em função de injunções externas ligadas ao trabalho, são casos hipotéticos da subjetividade, assim como a revolta, a resistência ou a retirada. E provavelmente são também bastante úteis e ricos para a qualidade da socialização subjetiva.

\section{Revista}

No livro Pourquoi travaillons-nous?, a senhora afirma que é justamente com a modernização do trabalho que as empresas operam uma verdadeira cisão com a sociedade. Em que medida seriam as próprias contradições da sociedade que geram esta cisão? Em que medida outras racionalidades circulariam dentro das empresas? Em que sentido a experiência do trabalho se modifica neste contexto de modernização do trabalho?

\section{Danièle Linhart}

É certo que, ao trabalhar, o trabalhador ganha a vida, mas busca também se relacionar com a sociedade, afirmar seu pertencimento à sociedade e se dirigir a ela. Na verdade, a modernização do trabalho que se pretenda também uma modernização do homem no trabalho é somente um passo a mais em sua domesticação somente às normas da racionalidade econômica e conduz a uma deformação de sua relação com o trabalho. A subjetividade dos assalariados é posta em jogo na relação de forças entre assalariados e empregadores, e cada vitória gerencial corresponde a um passo a mais na descaracterização do valor socializante do trabalho. Essa afirmação que pode parecer contraintuitiva, provocadora e ideológica leva em consideração um dos fundamentos do trabalho que E. Durkheim analisou de maneira magistral: sua dimensão altruísta. Trabalhar significa contribuir para a sociedade existir e este sentimento, presente na consciência coletiva, nutre toda relação com o trabalho. E. Durkheim 16 temia que a lógica taylorista, devido a um estilhaçamento das tarefas e da existência de restrições e controles, descaracterizaria essa dimensão altruísta, com os indivíduos arriscando-se a perder de vista a realidade de sua contribuição. Para ele, o taylorismo era uma anomalia da divisão social do trabalho. Mantendo-me na filiação de sua análise, que me parece fundamental, gostaria de questionar essa hipótese de uma dimensão dessocializante do trabalho que sofre a influência da lei taylorista. Não é o caso, como entendemos, de fazer a apologia da lógica taylorista, longe disso, mas somente de mostrar que, no universo taylorista, os assalariados, principalmente os operários, estavam em condições de apresentar essa dimensão altruísta que E. Durkheim analisava, de uma maneira certamente específica, mas bem real: ela se encontrava concentrada no seio dos coletivos, e moldada em uma vontade de transformação histórica da sociedade. Os operários fizeram a demonstração de uma relação com o trabalho taylorista em que se misturam contestação e implicação em uma forte ambivalência.17 A implicação produtiva encarnada na vontade de fazer bem o trabalho, contestação estimulada por um sentimento de injustiça de dimensão coletiva (a classe) e organizada em torno de um projeto político com perspectiva universal, nesse mundo do trabalho taylorista. A ideia de um destino comum solidifica uma relação vivida em um mundo essencialmente coletivo no trabalho e na sociedade.

O trabalho moderno tende a desfazer essa dimensão coletiva que garante o altruísmo. A estratégia patronal de individualização sistemática da gestão dos assalariados, que surgiu no início dos anos 1970, em reação e em resposta oportunista à contestação operária de maio de 1968, chegou à 
maturidade plena. O mundo do trabalho se transformou de maneira espetacular e é num contexto de forte individualização que se desenvolveram as novas formas de organização do trabalho que enfocam a mobilização subjetiva dos assalariados. Mas, poder-se-ia objetar, isso não poria o assalariado em embate direto com a sociedade? O apagamento dos coletivos (de suas culturas e valores orientados para a defesa de seus interesses), em prol de uma individualização, valorização das pessoas, não permitiria reatar com valores mais universais, mais orientados para a sociedade em seu todo? Não se vê assim emergir situações nas quais, com os assalariados se mobilizando de maneira mais autônoma e mais pessoal, a noção de abnegação e de contribuição à sociedade assumiria todo o seu sentido, principalmente o analisado por E. Durkheim? O que mostram as pesquisas de campo não vai nesse sentido. Longe de ser liberada, a postura altruísta inscrita na relação com o trabalho modernizado se vê, pelo contrário, desfigurada por meio de uma dupla solicitação, uma dupla orientação orquestrada de maneira imperiosa pelo gerenciamento modernista. A primeira leva os assalariados rumo a uma deriva narcísica, 18 desviando-os dessa consciência coletiva que os inscreve na sociedade, a segunda os subordina a uma causa partidária, a da única empresa na qual trabalham. As duas coisas andam juntas: é na mobilização ao serviço exclusivo de sua empresa que os assalariados são convidados a desenvolver o melhor de si mesmos, a se avaliar, a se comparar com os outros, para comprovar sua excelência, suas qualidades, toda a sua potência. Esse centramento na pessoa, bem como a pretensão da empresa de captar exclusivamente o sentido do trabalho, exigindo uma interiorização de sua causa pelo assalariado, causa um efeito sobre a qualidade da função socializante do trabalho, sobre sua dimensão altruísta.

Acho que uma parte do ressentimento (e talvez mesmo da raiva) dos assalariados do setor privado em relação aos funcionários do serviço público reside nessa atrofia do sentido e no âmbito do trabalho imposto no setor privado, assim como na frustração narcísica que ela gera. Os funcionários do setor público não continuam a se prevalecer do interesse geral, de missões do serviço público, enquanto que os assalariados do setor privado se sentem aprisionados no jugo dos interesses privados, amputados da dimensão uni- versal de sua contribuição, e, além disso, confrontados com um 'ideal de trabalho' impossível (para retomar a expressão de M. A. Dujarier). A forte resistência que muitos funcionários do serviço público opõem à modernização, que consiste em introduzir a lógica da administração do setor privado, só serve para exasperar os assalariados que se sentem expulsos de um mundo em que outros ainda têm o privilégio de morar.

Essas considerações, à primeira vista abstratas, nos colocam na pista do que são privados os indivíduos que não encontram emprego e do que sofrem os assalariados no contexto do trabalho moderno. Elas apresentam a questão do futuro de nossa sociedade, se julgamos fundamental o papel do trabalho no aprendizado da cidadania como na socialização dos indivíduos. Não se trata apenas de fratura social, mas de uma deriva que pode ser ainda mais inquietante, por ser invisível e silenciosa. É no momento que o trabalho se torna cada vez mais central que ele se torna, mais do que nunca, a atividade privilegiada que confere uma identidade, um lugar na sociedade, no momento em que as tentativas se homogeneizam a seu respeito, em que ele representa o principal vetor da cidadania, que ele sofre evoluções que questionam seus fundamentos.

Nesse sentido, acho que são as exigências das empresas que transformam a sociedade e não tanto o contrário. Como explicava bem Henry Ford, na época em que estava introduzindo as linhas de montagem nas fábricas de Detroit, era necessário criar um tipo específico de operário com um modo de vida adaptado à produção e ao consumo de massa, o que foi conceptualizado por Gramsci por meio do termo americanismo.

\section{Revista}

Na sua opinião, o setor público apresenta problemas semelhantes? Por exemplo, os profissionais que trabalham nas instituições públicas de saúde viveriam as mesmas dificuldades que os do setor privado?

\section{Danièle Linhart}

Assistimos, no âmbito da modernização que modela nosso mundo do trabalho há mais de 20 anos, a fenômenos surpreendentes e principalmente a uma troca de posições entre o setor público e o setor privado: os gerentes modernistas tentam, na verdade, importar a qualquer preço para o setor privado valores profissionais característicos do 
setor público no momento em que eles sofrem ataques devastadores da lógica gerencial privada. Os administradores do setor privado pós-1968 exerceram uma forte pressão. Era preciso, para enfrentar uma concorrência cada vez mais exigente, garantir uma mão de obra menos rebelde, menos disposta a contestar as modalidades de inserção no trabalho, uma mão de obra adapta$\mathrm{da}$ às exigências de um trabalho cada vez mais reativo. Era preciso, para manter o rumo, ter assalariados totalmente confiáveis, prontos para se comprometer a fundo com sua atividade, prontos para compreender o que se esperava deles e para fazer um uso de si mesmos o mais eficaz e mais rentável do ponto de vista de sua empresa. Eles necessitavam, então, de assalariados dedicados, comprometidos com sua causa e capazes de se dar totalmente ao trabalho.

Isso representou uma mudança considerável. Até então, os assalariados franceses, muito estimulados com a convicção de um antagonismo irredutível de interesses entre eles mesmos e seus patrões, investiam em seu trabalho não apenas uma identidade de produtor (com a vontade de fazer seu trabalho em função das regras do ofício e das promovidas pelos coletivos na busca de sentido), mas também uma identidade de classe, motriz de ações coletivas para mudar as coisas. Foi preciso que a partir daquele momento eles se identificassem com seu trabalho tal como sua empresa o define, que eles fizessem uma adesão à sua causa e aceitassem, numa relação de extrema lealdade, se dedicar a ela.

Os administradores franceses não descansaram e se lançaram em uma marcha de transformação de seus assalariados, sem duvidar de suas capacidades de erradicação dos vestígios de um passado marcado pela ideologia da luta de classes. Impondo, em marcha forçada, uma política da tábula rasa, uma política da amnésia, favorecida por uma revolução na linguagem que provocou o desaparecimento da noção de operário (substituído pelo termo 'operador', 'piloto' ou 'consultor' de instalações), mas também a noção de conflitos (os parceiros sociais estão lá para achar soluções), a administração tentou dar à luz a fórceps nas empresas uma ideologia mais harmoniosa, em que a ideia de conflitos de interesses irredutíveis não tem mais lugar e em que os indivíduos assalariados (e não coletivos) se engajam a fundo em seu trabalho pela causa da empresa. A situação do mercado de trabalho muito desfavorável aos assalariados, chantagem da guerra econômica, como o esfacelamento de ideologias alternativas, favorecem, é certo, essa tentativa audaciosa que consistia em impor relações sociais no seio da empresa, mas também uma nova relação de cada um com seu trabalho e com sua empresa.

Com o recuo, poder-se-ia dizer que a administração de certa forma alcançou seu intento. As organizações do trabalho estabelecidas testemunham uma capacidade gerencial de arrancar e orquestrar a implicação, o engajamento dos assalariados em seu trabalho. Essas organizações se caracterizam, com efeito, pela transferência aos assalariados das dificuldades de planejar o trabalho moderno e principalmente a difícil conciliação entre objetivos de produtividade e de qualidade, reatividade. Elas se caracterizam também por uma intensificação espetacular do trabalho. Os assalariados se mobilizam na verdade para atingir seus objetivos, só se rebelando raramente, e tendem a só contar consigo mesmos para merecer seu lugar. Vão retirar do fundo de si mesmos os recursos necessários para realizar suas missões. Parece que os administradores conseguiram importar para o seio do setor privado uma postura e um ethos profissional encontrados com frequência nos funcionários do setor público.

As pesquisas que tratam do trabalho no setor público mostram que o engajamento, a lealdade, a dedicação são qualidades propaladas, mesmo que não sejam exclusivas. Na verdade, essas pesquisas descrevem servidores com frequência muito engajados em seu trabalho, que se identificam com sua instituição, com suas missões, que são capazes de se dedicar, isto é, capazes de se engajar de forma desinteressada em sua atividade, capazes de se dar com vontade sem buscar um reconhecimento permanente. É preciso enfatizar que esses comportamentos não existem em todo lugar. Existem, e cada um de nós já teve essa experiência infeliz, funcionários que fazem corpo mole no trabalho, esmiuçadores, autoritários ou pouco escrupulosos. Mas a regra dominante não é esta, ela é, quando as condições permitem, uma consciência profissional moldada na especificidade do serviço público, que se afirma.

Os valores do serviço público estatal conseguem se realizar com êxito quando são trazidos por uma lógica profissional ou de conhecimento técnico, permitindo então uma identidade profissio- 
nal positiva e forte. Nesses casos, pode-se dizer que a possibilidade de os funcionários públicos se mobilizarem em nome de valores profissionais e do serviço público consegue compensar os efeitos negativos do rigor burocrático. Nos lugares em que a burocracia não impõe sua lei de forma rígida e onde a hierarquia não tenta controlar os servidores de forma particularmente pesada, isto é, quando o ofício ou o sentido do serviço público consegue conter a lógica burocrática e mantê-la em seu lugar de proteção contra as solicitações e as pressões, contra o arbitrário, percebe-se o desenvolvimento de práticas profissionais que se parecem muito com as que os administradores do setor privado cobiçam. Mas elas se inscrevem em uma lógica bem particular, um terreno bem específico.

Os servidores públicos declaram que experimentam um orgulho e, sobretudo, uma certa serenidade do fato de trabalharem nos quadros do serviço público. Mesmo que o trabalho deles em si pareça pouco qualificado, mesmo que ocupem na instituição um lugar subordinado, consideram que a tarefa deles contém em si uma importância e uma nobreza que implicam 'naturalmente' da parte deles em um engajamento e em uma vontade de fazer bem seu trabalho em todas as circunstâncias. Eles demonstram que estão 'a serviço do serviço público', que labutam com um sentido republicano ancorado em suas práticas, que contribuem para garantir a perenidade da sociedade. Não apenas o resultado de seu trabalho está ligado à sociedade e a seus fundamentos, como também as condições de seu trabalho, já que reivindicam uma tripla igualdade: 19 entre os usuários, entre os funcionários públicos e entre usuários e funcionários públicos. Cada setor tem sua especificidade, assim sendo, nos serviços das obras públicas, existe a ideia de contribuir para a continuidade do território construindo e mantendo estradas, pontes, enquadrando a edificação de casas. Nos Correios, há a ideia de contribuir para a existência do vínculo social, o que também acontece de certa forma na SNCF [Société Nationale des Chemins de Fer Français/Sociedade Nacional de Estradas de Ferro da França]. No Tesouro Nacional, existe a ideia de velar para que as contribuições dos cidadãos à sociedade se deem de forma justa por meio do pagamento de impostos, por exemplo. E por aí vai. Nessas situações, encontra-se um número significativo de funcionários que consideram que agem de acordo com sua mente e sua consciência, que interpretam as regras onipresentes em função do espírito do serviço público. Não se trata de querer passar a imagem de um setor sem problemas. Os funcionários reclamam com frequência de um trabalho insuficientemente reconhecido (muitos têm essa queixa), não negam a existência de funcionários preguiçosos ou aproveitadores, mas existe incontestavelmente um ethos profissional cujos fundamentos residem no fato de que eles sentem um vínculo forte que une seu trabalho, por mais desqualificado ou limitado que seja, à sociedade. Encontram-se vários exemplos disso no setor da saúde.

É esse o tipo de ethos profissional sonhado pelas empresas do setor privado para seus empregados. Mas é preciso, desde logo, dizer que o que elas conseguiram introduzir é uma variante deformada e inquietante desse modelo, uma declinação aberrante e fonte de mal-estar e de desequilíbrios. A estratégia da importação de uma ética da dedicação e do engajamento nas empresas do setor privado foi feita em condições bem específicas. Nunca foi o caso de deixar esse engajamento se fazer em nome de valores universais, em nome de uma contribuição desinteressada à sociedade, mas de enquadrá-lo de forma bem precisa para encerrá-lo no perímetro restrito da empresa e do registro narcísico, como indiquei acima.

O engajamento, a dedicação, a disponibilidade que a administração das empresas privadas exige (como qualidades do assalariado virtuoso que merece seu emprego) só se assemelham de longe aos dos funcionários do setor público e se referem a aspectos totalmente diferentes. Em um caso, o do setor público, os assalariados são estimulados pelo sentimento de fazer para os outros, para a sociedade, de desempenhar uma função que contribui para uma lógica de conjunto, permitindo-se colocar a questão das condições de seu trabalho não como uma questão puramente corporativista, mas como um problema da sociedade (os professores, como os ferroviários ou os funcionários dos hospitais, por exemplo, ligam as condições de seu trabalho à qualidade do serviço público prestado); em outro, assalariados em concorrência uns com os outros, intimados o tempo todo a provar sua dedicação à causa da empresa (mesmo que isso se dê em detrimento dos clientes e dos valores da sociedade) e num tête à tête solitário e frustrante com eles mesmos, em uma busca sempre inconclusa deles mesmos. 
Arrebatados pelos conflitos de valores (com frequência, o interesse da empresa contra o da sociedade, seu próprio interesse contra o dos outros), mergulhados na dúvida de seu valor real, estão sujeitos à autodepreciação.

\section{Revista}

Como as questões de gênero estão ligadas às dimensões subjetivas do trabalho?

\section{Danièle Linhart}

Essa questão da inscrição do gênero na subjetividade, eu não a trabalhei como tal. Ou melhor, deparei-me com ela nas pesquisas que mostravam como as mulheres reivindicavam condições de trabalho que lhes permitem abordar valores universais e se recusavam a ficar presas às especificidades do gênero. É o caso, por exemplo, das trabalhadoras do cuidado (care) solicitando formas de padronização de seu trabalho que lhes protegeria de um burn out gerado pelas exigências infindáveis de seus pacientes. É um referencial comum, regras de ofício, que elas solicitam à sociedade de alguma forma.

\section{Revista}

Como a senhora interpreta os casos de suicídio nas empresas francesas, como na Renault e na France Telecom, que foram divulgados em 2010? A senhora propõe uma discussão sobre a precariedade do ponto de vista da subjetividade. Qual seria ela?

\section{Danièle Linhart}

Defendo a ideia de uma precarização dos assalariados estáveis que se opera por meio de uma fragilização de sua subjetividade e que faz parte das intenções gerenciais. Percebe-se a multiplicação de reformas sistemáticas: reestruturações de serviços sob a forma de descentralização mais recentralização, redefinição das profissões, externalização de certas atividades que são mais tarde retomadas através de fusão de diferentes naturezas, relocações, deslocalizações geográficas. As mudanças permanentes visam a que os assalariados não possam tecer laços de cumplicidade nem com seus colegas, nem com seus chefes ou dirigentes (que também estão sujeitos a condições de mobilidade ferozes), nem mesmo com seus clientes, de forma que os assalariados não possam se apoiar em rotinas, que não se sintam à vontade entre eles, dentro da empresa, em seu trabalho. Eles têm sempre que reaprender, se adaptar, reinventar as modalidades necessárias para dominar sua atividade: saber com quem se pode contar, quais relações podem ser estabelecidas com os diferentes departamentos ou interlocutores. Reinventar rotinas, pois essas rotinas permitem aliviar o assalariado que pode se dedicar aos incidentes, aos imprevistos; elas são pontos de apoio ainda mais importantes porque se inscrevem em um contexto que se torna mais complexo e mais incerto. Com essa política de reformas sistemáticas, os assalariados estão em situação permanente de 'desaprendizagem' e reaprendizagem. 20

Romper com as referências, sacudir os hábitos, é evitar que se reformem os coletivos com seus poderes de contestação, é evitar que se reconstituam zonas de sombras, bases de um micropoder e de capacidade de resistência dos assalariados. É manter os assalariados em estado de insegurança, exigir que trabalhem sempre no máximo de suas possibilidades e tentar se superar sem descanso, aprender a só contar com eles mesmos. É assim, pensam as direções e hierarquia, que os assalariados se tornarão mais adaptáveis e, na realidade, mais fáceis de controlar e dominar.

Tal insegurança, mantida por um mercado de trabalho desfavorável aos assalariados, é, assim, destinada a compensar a mínima eficácia do taylorismo em matéria de restrição e controle dos assalariados. A desestabilização, a precarização do trabalho constrange o assalariado a se pôr à prova sozinho, a se validar permanentemente. A mobilidade, a avaliação sistemática e o isolamento são trunfos preciosos para sustentar a dominação cada vez maior sobre os assalariados, por mais estáveis que sejam seus empregos. A fixação de objetivos pessoais sobre a lógica do 'sempre mais' se torna, nesse contexto de precariedade e impotência, um verdadeiro pesadelo para vários assalariados.

As conversas individuais são uma causa de inquietação e de desestabilização. As razões disso são várias. Devido a sua forte mobilidade, os responsáveis não estão em situação de entender todo o escopo do trabalho dos assalariados que eles têm que avaliar: vários assalariados relatam o estado de ignorância no qual se encontram os responsáveis pela avaliação da realidade das situações de trabalho que eles têm que avaliar, sua incompreensão das restrições que pesam sobre as pessoas que eles têm que julgar, que observar. Essas conversas têm implicações bem 
reais sobre as gratificações, os treinamentos, os desenvolvimentos de carreira e, às vezes, até mesmo sobre a permanência na empresa. Os assalariados dizem apreender esses momentos em que se sentem avaliados, julgados, comparados com os outros sem que as bases dessa avaliação sejam claramente estabelecidas e justificadas. Um sentimento de precariedade se instala quando se adquire a convicção de estar sob julgamentos aleatórios e arbitrários.

O sentimento de abandono que os assalariados podem ter aparece em muitas pesquisas de campo. Os assalariados afirmam não achar apoio nem ajuda quando se acham confrontados com tensões organizacionais e objetivos contraditórios. A hierarquia não tem disponibilidade ou competência e eles ficam ao deus-dará na busca de soluções para os vários desafios que se acumulam. Isso gera uma angústia permanente, um estresse alto e a sensação de não estar protegido de um duro golpe que comprometeria seu futuro na empresa. Tudo isso agravado pela ausência de reconhecimento de seus esforços e realizações. Esses fenômenos estão muito presentes na France Télécom, onde dois sindicatos pouco habituados a cooperar (a CGC, sindicato tradicional de profissionais qualificados, e o Sud, sindicato muito crítico) criaram em 2007 um observatório do estresse e mobilidades forçadas (do qual faço parte como membro do conselho científico). Esse observatório se confrontou com um número crescente de suicídios no trabalho.

\section{Notas}

1 Entrevista realizada por Jussara Brito, pesquisadora da Escola Nacional de Saúde Pública Sergio Arouca, Fundação Oswaldo Cruz (Ensp/Fiocruz); Lúcia Rotenberg, pesquisadora do Instituto Oswaldo Cruz, Fundação Oswaldo Cruz (IOC/Fiocruz); Mary Yale Neves, professora no Departamento de Psicologia da Universidade Federal Fluminense (UFF); e Simone Oliveira, pesquisadora da Escola Nacional de Saúde Pública Sergio Arouca, Fundação Oswaldo Cruz (Ensp/Fiocruz)), em outubro de 2010. Tradução do texto original em francês de Teresa Dias Carneiro.
A versão em francês está disponível no fascículo n. ${ }^{\circ} 1$ do volume 9 de Trabalho, Educação e Saúde, na página www.revista.epsjv.fiocruz.br.

2 Pratiques et connaissances ouvrières dans l'industrie capitaliste, Centre de Sociologie Historique, Lyon 1975.

3 Un travail à soi, Privat, Toulouse, 1981.

4 L'appel de la sirène ou l'accoutumance au travail, Le Sycomore, 1981.

5 Les règles du jeu, l'action collective et la régulation sociale, Armand Colin, 1989.

6 Autonomie dans le travail, PUF, 1992.

7 Principalmente Michael Burawoy, nos Estados Unidos, Manufacturing consent, University of Chicago Press, 1979 ; e, na França, D. et R. Linhart, "Naissance d'un consensus: la participation des travailleurs", in D. Bachet (Ed.), Décider et agir au travail, CESTA, 1985.

8 Por exemplo, Vincent de Gaulejac, La société malade de la gestion, le Seuil, 2005 ; E. Enriquez, Les jeux du pouvoir et du désir en entreprise, Desclée de Brower, 1997; D. Linhart, Le torticolis de l'autruche; l'éternelle modernisation des entreprises françaises, Le Seuil, 1991.

9 A. Salmon, La tentation éthique du capitalisme, La Découverte, 2007 e também Ethique et ordre économique, CNRS Editions, 2002.

10 J.P. Durand, La chaîne invisible. Travailler aujourd'hui; flux tendu et servitude volontaire, Le Seuil, coll. Economie Humaine, 2004.

11 Ver o livro de mesmo título, PUF, coll. Partage du savoir-Le Monde, 2006.

12 Érès, 2008.

13 Le Seuil, 2010.

14 Ver Cliniques du travail, Érès, 2007, p. 189.

15 Ver artigo de autoria de Clot, “Clinique du travail et clinique de l'activité", in Y. Clot et D. Lhuilier (Eds.), Perspectives en clinique du travail, Nouvelle 
Revue de Psychosociologie, mai. 2006; ver também a introdução a Louis Le Guillant, Le drame humain du travail, Érès, Clinique du travail, 2006.

16 La division sociale du travail, lère édition 1930, PUF, 2004.

17 Ver D. Linhart, L'appel de la sirène ou l'accoutumance au travail, Le Sycomore, 1981.

18 Ver V. de Gaulejac, La gestion contre la société, Le Seuil, 2006, e M. A. Dujarrier, L'idéal du travail, Le Monde PUF, 2006.

19 Ver o artigo de Aurélie Jeantet: “À votre service, la relation de service comme rapport social", Sociologie du travail, n. 45, 2003.

20 Ver J.L. Metzger, Entre utopie et résignation: la réforme permanente d'un service public, Coll Logiques Sociales, L'Harmattan, 1999. 